\title{
Functional expression of the sweet-tasting protein brazzein in transgenic tobacco
}

\author{
Hyo-Eun $\mathrm{CHOI}^{1}$, Ji-In LEE ${ }^{1}$, Seon-Yeong JO${ }^{1}$, Yun-Cheol CHAE², Jeong-Hwan LEE ${ }^{3}$, Hyeon-Jin SUN ${ }^{4}$, Kisung $\mathrm{KO}^{3}$, \\ Sungguan $\mathrm{HONG}^{1 *} \mathbb{D}$, Kwang-Hoon $\mathrm{KONG}^{1 *}$
}

\begin{abstract}
The sweet-tasting protein, brazzein, has potential as a low-calorie sugar substitute owing to its high sweetness, stability, and water solubility. In this study, the synthetic brazzein gene was expressed in the tobacco plant, Nicotiana tabacum. Three types of expression cassettes containing the brazzein gene were constructed to examine the expression and purification efficiency of the brazzein: pBI-BZ1 containing a signal sequence and His-tag, pBI-BZ2 containing a signal sequence, and pBI-BZ3 containing only the brazzein gene. Brazzein expression confirmed by ELISA was purified using ammonium sulfate precipitation, heat treatment, and CM-sepharose chromatography. The purity and conformational state of the brazzein were confirmed using SDS-PAGE, HPLC, and circular dichroism. The identity of the brazzein was confirmed by N-terminal amino acid analysis, ESI-MS/MS, and sweetness analysis. We successfully generated brazzein overexpression tobacco plants, suggesting that this method could be used as a brazzein production platform to provide an alternative to currently produced sweeteners.
\end{abstract}

Keywords: alternative sweetener; brazzein; Agrobacterium-mediated transformation; transgenic tobacco plant; protein purification.

Practical Application: Our study provides an economic mass-production system for this sweet-tasting protein, brazzein, with potential use as an alternative sweetener in the food industry.

\section{Introduction}

The appeal sweet food is undeniable, however, excessive sugar and artificial sweetener intake has contributed to several diseases including hypertension, diabetes, and obesity (Kant, 2005). Therefore, the development of alternative sweeteners is required. Eight proteins are known to elicit sweetness, and these include brazzein, curculin/neoculin, egg white lysozyme, mabinlin, miraculin, monellin, pentadin, and thaumatin (Wintjens et al., 2011). These proteins have the potential to replace sugar and artificial sweeteners by acting as natural, healthy, and low-calorie sweeteners. The smallest protein among them, brazzein, possesses a high sweetness intensity, pleasant sweet taste profile, and good stability at both high temperature with its sweetness persisting even after heating at $80^{\circ} \mathrm{C}$ for $4.5 \mathrm{~h}$ and in a wide $\mathrm{pH}$ range (Ming \& Hellekant, 1994) (Lee, et al., 2010). These attributes make it worthwhile to explore brazzein as a candidate sweetener.

Brazzein was isolated in two forms from the fruit pulp of Pentadiplandra brazzeana Baillon, a climbing vine that grows in West Africa (Ming \& Hellekant, 1994). The major form is a single polypeptide of 54 amino acid residues and contains a pyroglutamate at its $\mathrm{N}$-terminus, while the minor form lacks this pyroglutamate residue at the $\mathrm{N}$-terminus. The major form is approximately 2000 times sweeter than a $2 \%$ sucrose solution, and 9500 times sweeter than sucrose on a molar basis
(Assadi-Porter et al., 2000). The minor form has nearly twice the sweetness as the major form.

Unfortunately, the commercial production of brazzein from its natural source is limited, as it comes from a tropical plant that is difficult to cultivate outside its natural environment. Thus, numerous attempts to produce brazzein in microorganisms have been made in Escherichia coli (Assadi-Porter et al., 2008), Lactococcus lactis (Berlec et al., 2006), and Mus musculus (Yan et al., 2013). These previous studies reported that attempts at brazzein production resulted in low sweetness intensity, productivity, and overall yield. Recently, brazzein expression was attempted in Kluyveromyces lactis and Pichia pastoris yeasts, which are "generally regarded as safe" (GRAS); the purified brazzein was obtained in a soluble and active form in the approximate range of 30-100 $\mathrm{mg} \mathrm{L}^{-1}$ (Jo et al., 2013; Poirier et al., 2012; Yun et al., 2016). Transgenic plant systems have been used to produce recombinant proteins for pharmaceutical and industrial purposes with advantages including simple medium and culture condition requirements (Pham et al., 2012). Brazzein production in transgenic maize has been attempted but resulted in cross-contamination (Lamphear et al., 2005). Brazzein expression in transgenic rice is also under study (Lee et al., 2018). Despite the existence of these studies, a proper transgenic plant system for brazzein production is still needed. 
Herein, we attempted to produce brazzein in the tobacco plant, Nicotiana tabacum. To improve brazzein production level and purification yield, we designed and constructed three types of expression cassettes containing the codon that optimizes the brazzein gene for protein production in the plants. Expression of brazzein in tobacco plants was confirmed, and the expressed soluble brazzein was purified from plant. Its purity and conformational state were evaluated, and the identity of the brazzein was also confirmed. Brazzein in a soluble form with high yield and functional activity was successfully expressed in the transgenic tobacco plant.

\section{Materials and methods}

\subsection{Expression vector construction}

In order to produce brazzein in $N$. tabacum $\mathrm{cv}$. Xanthi, the gene encoding the minor form of brazzein (NCBI Accession No. EU883595), which lacks an $\mathrm{N}$-terminal pyroglutamate residue, was designed and synthesized with optimized codon usage for expression in a tobacco plant (Figure 1). Three types of expression cassettes containing the brazzein gene were also designed and constructed to provide a higher expression

A

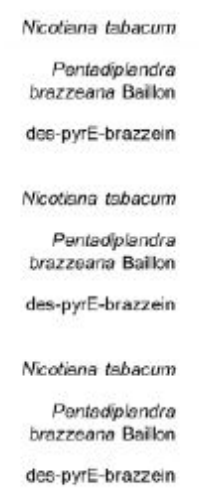

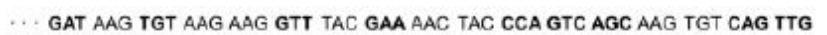

CAG GAC AAG TGC AAG AAG GTC TAC GAG AAC TAC CCC GTG TCC AAG TGT CAA CTG

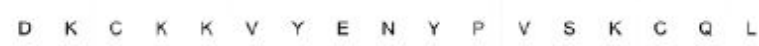

GCG AAC CAA TGT AAT TAC GAC TGC AAG TTG GAC AAA CAT GCC CGT TCG GGAGAG

GCT AAT CAG TGC AAC TAC GAT TGC AAG CTC GAC AAG CAC GCT CGC TCC GGC GAA

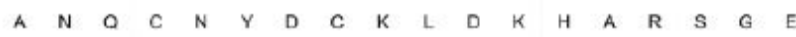

TGC TTC TAT GAT GAG AAA CGC AAT CTC CAG TGC ATT TGC GAC TAC TGC GAG TAT

TGC TTC TAC GAT GAG AAG CGC AAC CTG CAG TGC ATT TGC GAC TAC TGC GAG TAC

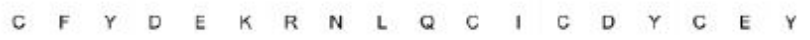

51

54

17

105

108

35

159

162

53

B

Nicotana tabacum

‥ GAT AAG TGT AAG AAG GTC TAC GAG AAC TAC CCA GTT TCC AAG TGT CAG CTC

51

Pantadiplandra brazzeane Bailon dec-pyrE-brazzein

Nicotiana tabacum

Pentadiplendra brazzeana Baibm dee-pyrE-brazzein

Nicotiana tabacum

Pentediplendra brazzeana Bailon des-pyrE-brazzein

CAG GAC AAG TGC AAG AAG GTC TAC GAG AAC TAC CCC GTG TCC AAG TGT CAA CTG

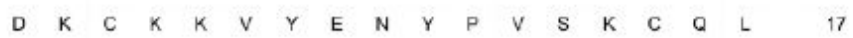

GCG AAC CAA TGT AAT TAC GAC TGC AAG CTC GAT AAA CAC GCC CGT TCG GGA GAA 105 GCT AAT CAG TGC AAC TAC GAT TGC AAG CTC GAC AAG CAC GCT CGC TCC GGC GAA 108

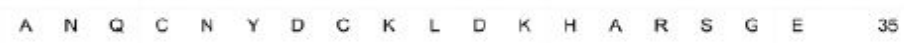

TGC ITT TAT GAC GAG AAA CGC AAT CTG CAG TGC ATT TGC GAC TAC TGCGAG TAT $\quad 159$ TGC TTC TAC GAT GAG AAG CGC AAC CTG CAG TGC ATT TGC GAC TAC TGC GAG TAC 162

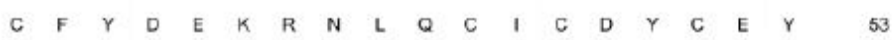

C

Nicotana tabacum
Pantodiplandra
brazzeana Bailon
des-pyrE-brazzein
Nicotiana tabacum
Pentadiplendra
brazzeana Baibon
des-pyre-brazzein
Nicotiana tabacum
Pentediplendra
brazzeana Bailon
des-pyrE-brazzein

Figure 1. Optimized brazzein sequence by codon usage. The optimized brazzein sequence by codon usage in transgenic tobacco plants, the original sequence in Pentadiplandra brazzeana Baillon, and the amino acid sequence of the brazzein minor form. The bold entries indicate the codons optimized in this study. (A) pBI-BZ1; (B) pBI-BZ2; (C) pBI-BZ3. 
level and better purification yield (Figure 2A, B). Expression cassette 1 was fused with the signal peptide (SP) sequence (SMATQRRANPSSLHLITVFSLLAAVVSAEVD) to facilitate the insertion of proteins into the membrane of the endoplasmic reticulum (Kang et al., 2017). Cassette 1 was also tagged with a His-tag to facilitate purification, and the tobacco etch viral 5'-leader sequence (TEV) was inserted at ends of the brazzein gene sequence to minimize any effect on the sweetness activity of brazzein. Cassette 2 contained the SP and the brazzein gene, and cassette 3 contained only the minor type brazzein gene. These expression cassettes $(1,2$, and 3$)$ were subcloned into $\mathrm{NcoI}$ and BamHI sites of the pBI-525 vector (Datla et al., 1993), which contained the cauliflower mosaic virus (CaMV) $35 \mathrm{~S}$ promoter and alfalfa mosaic virus RNA4 (AMV). These constructs were subcloned into HindIII and EcoRI sites of the binary plant transformation vector pBIN-Plus to yield pBI-BZ1, pBI-BZ2, and $\mathrm{pBI}-\mathrm{BZ} 3$, respectively (Figure $2 \mathrm{~A}, \mathrm{~B}$ ).

\subsection{Transgenic tobacco plant}

The transgenic tobacco plant for expression of Brazzein was Nicotiana tabacum Xanthi, which have been applied for many basic and applied researches in a lab at Chung-Ang University. The lab was certified for growth of transgenic tobacco plants as a living modified organism (LMO) including tobacco, Arabidopsis, and other plants by National Research Safety Information System, Korean Ministry of Science and ICT, and operated by Kisung Ko (professor at Medical College at Chung-Ang University). The certified number is LML13-315. Thus, we have permissions to grow the transgenic tobacco plant for research purpose under the government supervision. We have annually evaluated by the government.

\subsection{Analysis of tobacco plants for transformation}

The resulting recombinant vectors were introduced into the Agrobacterium tumefaciens strain LBA4404 by electroporation. Transgenic tobacco plants were generated by Agrobacterium-mediated transformation (Song et al., 2019). Transgenic tobacco lines were selected on conditioned medium (Shin et al., 2019) containing $100 \mathrm{mg} \mathrm{L}^{-1}$ kanamycin. Transgenic plantlets were then transferred to soil in a growth chamber at a constant temperature of $25^{\circ} \mathrm{C}$ and $70 \%$ humidity and maintained under a 16:8 h light-dark photoperiod of light emitting diode (LED)-fluorescent light. A series of 15 plants were grown from each independent transformation event.

\subsection{Polymerase chain reaction (PCR) analysis of genomic DNA}

Genomic DNA was isolated from $100 \mathrm{mg}$ of the fresh leaf tissue of transgenic and non-transgenic tobacco plants using a DNeasy Plant Mini Kit (Qiagen, Hilden, Germany), according to the manufacturer's instructions. PCR amplification of genomic DNA was performed to confirm the presence of brazzein genes using the following primer pairs: for $\mathrm{pBI}-\mathrm{BZ} 1$ and $\mathrm{pBI}-\mathrm{BZ2}$, forward primer 5'-GAT AAG TGC AAG GTT TAC GAG-3' and reverse primer 5'-ATA CTC GCA GTA GTC GCA GAT-3'; for pBI-BZ3, forward primer 5'-GAC AAG TGT AAG GTG TAC-3' and reverse primer 5'-ATA CTC GCA GTA GTC GCA GAT-3'. The presence of the NPTII gene in pBI-BZ1, pBI-BZ2, and $\mathrm{pBI}-\mathrm{BZ} 3$ was confirmed by PCR using the following primer pairs: forward primer, 5'-ATG ATT GAA CAA GAT GGA TTG CAC-3' and reverse primer, 5'-TCA GAA CTC GTC AAG G-3'.

A

B
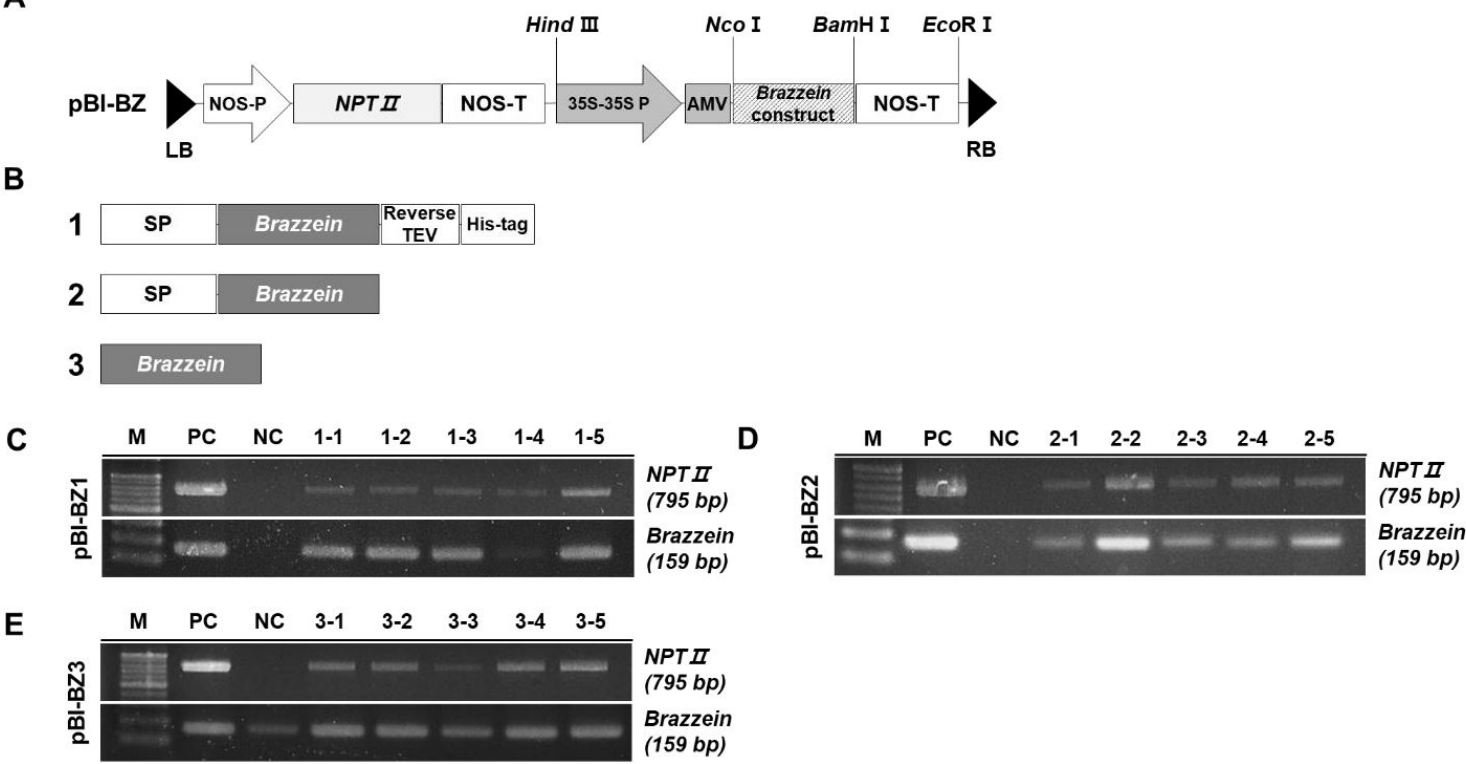

Figure 2. Confirmation of the T-DNA insertion in transgenic tobacco plants by PCR analysis. (A, B) Schematic diagram of the T-DNA region of binary vectors pBI-BZ1, pBI-BZ2, and pBI-BZ3. LB and RB, left and right border sequences of an Agrobacterium tumefaciens Ti plasmid; NOS-P = nopaline synthase gene promoter; NPTII = neomycin phosphotransferaseII; NOS-T = nopaline synthase terminator; $35 \mathrm{~S}-35 \mathrm{~S} \mathrm{P}=$ cauliflower mosaic virus (CaMV) dual-35S promoter; AMV = alfalfa mosaic virus RNA4; SP = endoplasmic reticulum signal peptide; TEV = untranslated leader sequence of tobacco etch virus; (C-E) The genomic DNA from 15 transgenic tobacco plants (1-1 to 3-5), a positive control (PC, plasmid DNA template), and a negative control (NC, wild-type tobacco sample) were used as the templates for PCR analysis. $\mathrm{M}=100$ bp plus DNA ladder. 
Non-transgenic plant samples were used as a negative control, while plasmid DNA template was used as a positive control. All PCR amplifications were performed using a Maxime PCR PreMix Kit (i-StarTaq) (Intron Biotechnology, Seongnam, Korea). After amplification, the products were separated on $2 \%$ agarose gels at $100 \mathrm{~V}$ for $30 \mathrm{~min}$ and visualized by ethidium bromide staining.

\subsection{Quantitative real time PCR ( $q R T-P C R)$ analysis}

For pBI-BZ2 with high brazzein expression as determined by ELISA, the transcript levels of $p B I-B Z 2 \mathrm{mRNA}$ were quantified by qRT-PCR. Total RNA was isolated from transgenic tobacco leaves using TRIzol reagent (Invitrogen, Carlsbad, CA, USA). Complementary DNA (cDNA) was synthesized from $1 \mu \mathrm{g}$ of total RNA using a QuantiTect Reverse Transcription Kit (QIAGEN GmbH, Hilden, Germany). The relative mRNA expression of pBI-BZ2 was analyzed via $\mathrm{qRT}$-PCR using the following primers: forward primer 5 '- ACG ACT GCA AGC TCG ATA AA-3' and reverse primer 5'- TAC TCG CAG TAG TCG CAA ATG-3'. Brazzein expression level was normalized by $N$. tabacum elongation factor 1-alpha $(E F-1 \alpha)$ using the following primers: forward primer 5'- GTC AAG AAT GTT GCG GTT AAG G-3' and reverse primer 5'- TGA TAG CTT GGG AGG TAA AG-3' using SYBR Green with low ROX (Enzynomics, Daejeon, Korea) Relative mRNA quantitation was determined based on the comparative cycle threshold method $2^{-\Delta \Delta \mathrm{Ct}}$, with $\mathrm{Ct}$ values obtained using Real-Time MY-IQ (Bio-Rad, Hercules, CA, USA). A non-transgenic plant was used as a negative control, and each sample was assayed in triplicate.

\subsection{Preparation of anti-brazzein antibody and enzyme-linked immunosorbent assay}

Anti-brazzein antibody was prepared as follows: the minor form of brazzein was produced in K. lactis yeast using pKLAC2 (Yun et al., 2016) and used to raise antiserum in New Zealand White rabbits with the assistance of ProSci Incorporated (San Diego, CA, USA). Rabbit anti-brazzein antibody was purified by fractionation with ammonium sulfate ( $40 \%$ saturation) followed by rProtein A-agarose affinity chromatography (Amicogen, Jinju, Korea).

The brazzein accumulation levels in transgenic tobacco plants were determined using an indirect enzyme-linked immunosorbent assay (ELISA). Transgenic tobacco leaves were homogenized in three volumes of $1 \times$ PBS buffer and centrifuged at $15000 \times \mathrm{g}$ for $1 \mathrm{~min}$ at $4{ }^{\circ} \mathrm{C}$, then the supernatants were subjected to ELISA. Supernatant protein concentrations were determined using a Pierce ${ }^{\mathrm{m}}$ BCA Protein Assay Kit (Thermo Scientific, Erembodegem, Belgium). Briefly, plates were coated with soluble protein extracts $\left(1 \mathrm{mg} \mathrm{mL}^{-1}\right.$ per well) and blocked using blocking buffer [PBS-T containing 3\% bovine serum albumin (BSA) (Bioworld, Dublin, OH, USA)] Rabbit anti-brazzein polyclonal antibody (1:2000 dilution, ProSci, San Diego, CA, USA) was added to the wells and incubated at $37^{\circ} \mathrm{C}$ for $2 \mathrm{~h}$, followed goat poly anti-rabbit IgG (H\&L) conjugated with HRP (1:10 000 dilution, Komabiotech, Seoul, Korea) for $2 \mathrm{~h}$. Samples were washed four times and then treated with 3.3', 5.5'-tetramethylbenzidine (TMB) (Seracare, Milford, MA, USA) for $5 \mathrm{~min}$. The reaction was stopped by adding TMB stop solution (Seracare, Milford, MA, USA). The absorbance at $450 \mathrm{~nm}$ was recorded using a UVM340 microplate reader (Biochrom, Holliston, MA, USA). To determine the amount of brazzein in transgenic tobacco plants, a brazzein standard curve was established using duplicate measurements of the recombinant yeast-derived brazzein solution (Chung et al., 2018) and nontransgenic negative tobacco plant control samples were included in the assay for reference.

\subsection{Isolation and purification of brazzein from transgenic tobacco plants}

The T1 generation transgenic tobacco plants containing pBI-BZ2 had the highest brazzein expression level of the expression cassettes. Therefore, we extracted and purified the brazzein from the pBI-BZ2 T1 generation of transgenic tobacco plants. Ammonium sulfate precipitation, heat treatment, DEAE-sepharose anion exchange chromatography, and CM-sepharose cation exchange chromatography were applied as possible methods for efficient and low-cost brazzein purification. Tobacco leaves were homogenized in extraction buffer $(40 \mathrm{mM}$ Tris- $\mathrm{HCl}$, $50 \mathrm{mM} \mathrm{NaCl}, 20 \mathrm{mM}$ EDTA, $55 \mathrm{mM}$ sodium citrate, and $12 \mathrm{mM}$ sodium thiosulfate, $\mathrm{pH}$ 6.7) at a ratio of $1: 3.5 \mathrm{~g} \mathrm{ml}^{-1}$ using a Multi cutter mk-240 (Panasonic, Osaka, Japan). After centrifugation at $6000 \times \mathrm{g}$ for $30 \mathrm{~min}$ at $4{ }^{\circ} \mathrm{C}$, the supernatant was filtered through a Miracloth (Biosciences, La Jolla, CA, USA). To remove chlorophyll, the filtered supernatant was reduced to $\mathrm{pH} 4.0$ by adding acetic acid, centrifuged at $7000 \times g$ for $30 \mathrm{~min}$ at $4{ }^{\circ} \mathrm{C}$, and filtered in the same manner.

To investigate the specific percentage saturation of ammonium sulfate required for brazzein purification, saturated ammonium sulfate was added to the supernatant at $10 \%$ intervals from 0 and $90 \%$ saturation and stirred gently for $12 \mathrm{~h}$ at $4{ }^{\circ} \mathrm{C}$. The precipitates in each saturated solution were obtained by centrifugation at $15000 \times \mathrm{g}$ for $30 \mathrm{~min}$, dialyzed in distilled water, and analyzed by SDS-PAGE. Heat treatment was carried out using a $30-80 \%$ saturated solution dialyzed against distilled water in a Cellu-Sep T1 dialysis tube ( $3.5 \mathrm{kDa}$ cut-off; Membrane Filtration Products, Seguin, TX, USA) at $80^{\circ} \mathrm{C}$ for $1,2,3$, and $4 \mathrm{~h}$. After heat treatment, samples were centrifuged at $15000 \times \mathrm{g}$ for $30 \mathrm{~min}$ to separate the supernatant and pellet.

DEAE-sepharose anion exchange (GE Healthcare, Little Chalfont, UK) chromatography was carried out using a 30-80\% saturated solution dialyzed against $20 \mathrm{mM}$ Tris- $\mathrm{HCl}(\mathrm{pH} 8.0)$ in a Cellu-Sep T1 dialysis tube. The column was washed with 10 column volumes of $20 \mathrm{mM}$ Tris- $\mathrm{HCl}$ ( $\mathrm{pH}$ 8.0) and eluted with a gradient from 0 to $1.0 \mathrm{M} \mathrm{NaCl}$ in $20 \mathrm{mM}$ Tris- $\mathrm{HCl}$ ( $\mathrm{pH} 8.0$ ). The flow rate was $1 \mathrm{ml} \mathrm{min}^{-1}$ at each step.

CM-sepharose cation exchange (GE Healthcare, Little Chalfont, UK) chromatography was performed using the solution containing brazzein from DEAE-sepharose chromatography dialyzed against $50 \mathrm{mM}$ sodium acetate ( $\mathrm{pH}$ 4.0) in a Cellu-Sep $\mathrm{T} 1$ dialysis tube. The column was washed with $50 \mathrm{mM}$ sodium acetate buffer ( $\mathrm{pH} 4.0)$ containing $50 \mathrm{mM} \mathrm{NaCl}$ and eluted with the same buffer containing $400 \mathrm{mM} \mathrm{NaCl}$ at a flow rate of $3 \mathrm{ml}$ $\min ^{-1}$. The degree of purity was evaluated by SDS-PAGE. 


\subsection{Determination of protein concentration and SDS-PAGE}

Protein concentration was determined by BCA assay reagent (Pierce Chemical Co., Rockford, IL, USA) using bovine serum albumin as the standard protein. SDS-PAGE was performed with $16.5 \%$ Tris-tricine gels to evaluate the purity of the purified brazzein as previously described (Yun et al., 2016). Precision Plus Protein $^{\mathrm{TM}}$ Dual Xtra Prestained Standards (Bio-Rad, Hercules, CA, USA) were used as molecular-mass markers. Coomassie Blue R-250 was used for protein staining.

\subsection{Reversed-phase HPLC and circular dichroism analysis}

Reversed-phase HPLC column chromatography was used to confirm the purity of the folded brazzein. The purified brazzein was subjected to Prominence HPLC (Shimadzu, Kyoto, Japan) testing using an Extend-C18, Zorbax column $(5 \mu \mathrm{m}, 4.6 \times 250 \mathrm{~mm}$, Agilent, CA, USA). The eluting solvents used for separation were acetonitrile containing $0.1 \%$ aqueous formic acid (solvent-A) and ammonium formate (solvent-B) with a linear gradient from 20 to $80 \%$. The flow rate was $0.3 \mathrm{ml} \mathrm{min}^{-1}$, detected at $210 \mathrm{~nm}$.

The conformational state of the brazzein was confirmed using circular dichroism (CD) analysis. CD spectra of the purified brazzein expressed in N. tabacum and K. lactis were measured with a J-815 spectropolarimeter (Jasco Co., Tokyo, Japan) at $25^{\circ} \mathrm{C}$ in distilled water as previously described (Jo et al., 2013). Far-UV CD spectra were measured at a protein concentration of $10 \mu \mathrm{M}$ with a 1 -mm cell from 180 to $260 \mathrm{~nm}$. Measurements were expressed as the mean residue ellipticity, $[\theta]_{\mathrm{Mr}}$, with a mean residue weight (Mr) of 120 for brazzein. The data were collected three times and represented as the average mean residue ellipticity.

\subsection{N-terminal amino acid sequencing and ESI-MS/MS analysis}

The identity of brazzein was confirmed by N-terminal amino acid analysis and liquid chromatography electrospray ionization tandem mass spectrometric analysis (LC-ESI-MS/MS). The purified brazzein was transferred to polyvinylidene difluoride (PVDF) membranes by dot blotting. Bands were visualized by staining with GelCode Blue, excised from PVDF, and subjected to automated Edman degradation using an API492 Procise protein sequencer (Applied Biosystems, Foster City, CA, USA) at eMass Incorporated (Seoul, Korea). ESI-MS/MS analysis was performed by ProteomeTech Incorporated (Seoul, Korea) using a nano ACQUITY UPLC and LTQ-orbitrap-mass spectrometer (Thermo Electron, San Jose, CA, USA).

\subsection{Analysis of the sweetness properties}

Brazzein sweetness was assayed by sensory analysis using a double-blind test with 15 individuals, as previously described (Jo et al., 2013). The sweetness potencies were reported as relative to sucrose on a molar basis.

\subsection{Statistical analysis}

All data are expressed as the mean \pm SEM of three or more independent experiments. Statistical significance $(\mathrm{P}<0.05)$ was calculated using Microsoft Excel. Differences between samples were evaluated using Student's t-test.

\section{Results}

\subsection{Generation of transgenic tobacco plants}

Transgenic plants were generated from tobacco explants inoculated with $A$. tumefaciens strain LBA4404 carrying plant expression vectors $\mathrm{pBI}-\mathrm{BZ1}$, pBI-BZ2, and pBI-BZ3 (Figure 2A, B), as confirmed by sequencing (Macrogen, Seoul, Korea). Putative transformants were selected by kanamycin antibiotic. T-DNA integration was confirmed by PCR via amplification of NPTII and brazzein genes using the genomic DNA as a template. The data showed that all brazzein constructs were inserted into the genome (Figure 2C-E). Therefore, transgenic plants that contained $\mathrm{pBI}-\mathrm{BZ} 1, \mathrm{pBI}-\mathrm{BZ} 2$, and $\mathrm{pBI}-\mathrm{BZ} 3$ were generated and subjected to the following experiments.

\subsection{Brazzein expression in transgenic tobacco plants}

Brazzein expression in transgenic tobacco plants was confirmed by ELISA. Leaf extracts from pBI-BZ1 transgenic lines (1-1, 1-2, 1-3, 1-4, and 1-5), pBI-BZ2 transgenic lines (2-1, 2-2, 2-3, 2-4, and 2-5), and pBI-BZ3 transgenic lines (3-1, 3-2, $3-3,3-4$, and $3-5)$ were analyzed by ELISA. Both pBI-BZ1 and pBI-BZ2 transgenic lines showed significantly greater absorbance than $\mathrm{PBI}-\mathrm{BZ} 3$ transgenic lines, in which the recombinant brazzein was expressed in the cytoplasm (Figure 3A-C). In addition, brazzein mRNA expression in pBI-BZ2 transgenic lines was confirmed by qRT-PCR using the total RNA isolated from two selected transformed pBI-BZ2 lines (Supplementary Figure S1).

Brazzein expression in the $\mathrm{T} 1$ generation of transgenic tobacco plants was detected in $\mathrm{PBI}-\mathrm{BZ} 1$ and $\mathrm{pBI}-\mathrm{BZ} 2 \mathrm{~T} 1$ progeny by ELISA (Figure 3D, E). In T1 generation transgenic tobacco plants, the brazzein expression level in pBI-BZ2 samples was higher than that of $\mathrm{pBI}-\mathrm{BZ} 1$, showing expression amounts ranging from approximately 39.1 to $57.9 \mathrm{mg} \mathrm{kg}^{-1}$ fresh weight (Table 1).

\subsection{Purification of brazzein from transgenic tobacco plants}

Expressed recombinant brazzein purification resulted in brazzein precipitation from crude transgenic tobacco leaf extract at $30-80 \%$ ammonium sulfate saturation, but brazzein did not form a precipitate between 0 and $30 \%$, or above $80 \%$ (Supplementary Figure S2A). Brazzein purification by heat treatment obtained maximum purity and yield by heating at $80^{\circ} \mathrm{C}$ for $2 \mathrm{~h}$ (Supplementary Figure S2B). Heating for longer than $3 \mathrm{~h}$ caused brazzein denaturation and precipitation without increasing the purity of the expressed brazzein. This result suggests that heat treatment is appropriate for brazzein

Table 1. Confirmation of brazzein concentration in transgenic tobacco plants by ELISA. Brazzein concentration was determined for the protein extract obtained from pBI-BZ2 transgenic tobacco plants. The results were obtained from four independent experiments.

$\begin{array}{cr}\mu \mathrm{g} \text { brazzein } \mathrm{g}^{-1} \text { fresh weight } & 46.94 \\ \mathrm{mg} \text { total soluble protein } \mathrm{g}^{-1} \text { fresh weight } & 9.20 \\ \mu \mathrm{g} \text { brazzein } \mathrm{mg}^{-1} \text { total soluble protein } & 5.12\end{array}$



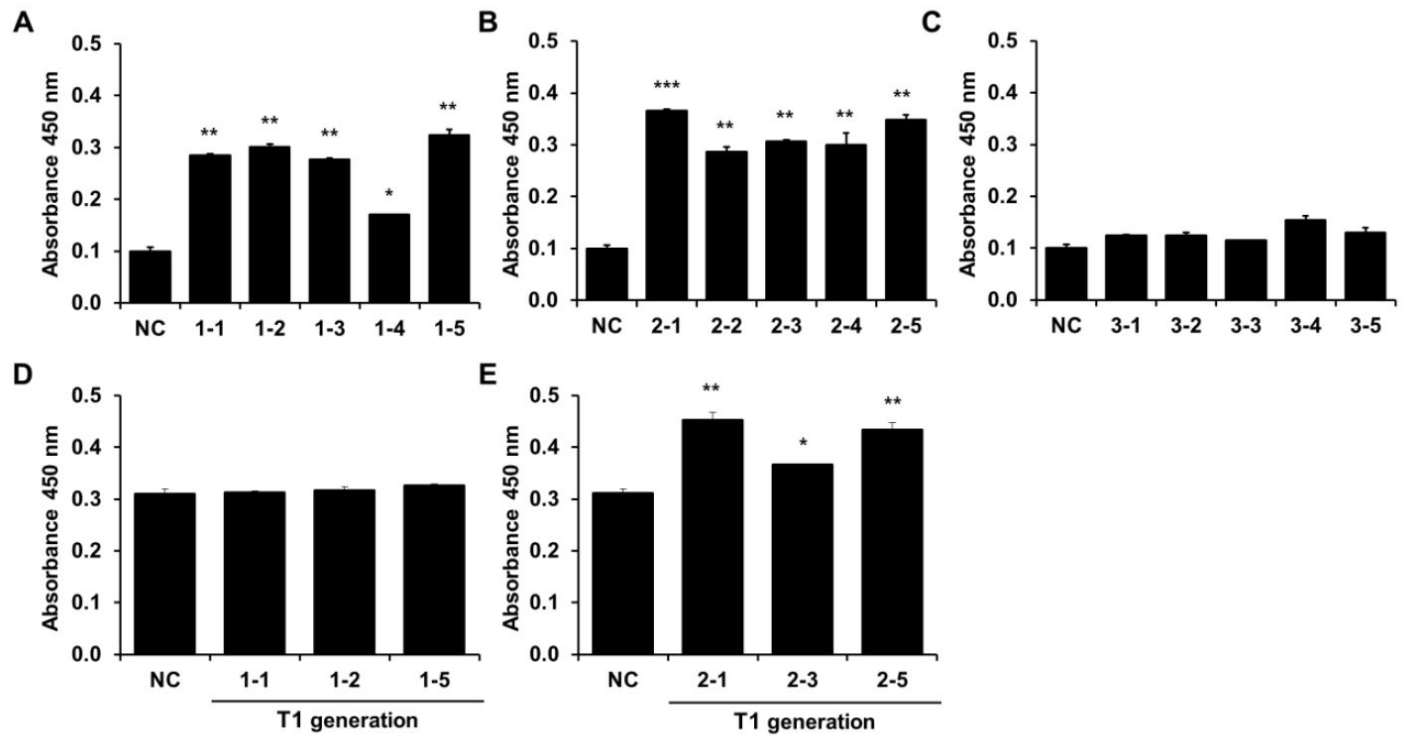

Figure 3. Confirmation of the brazzein protein expression level in transgenic tobacco plants. Expression levels of brazzein protein were measured by ELISA. The ELISA data shows brazzein protein level compared to a negative control (NC, non-transgenic tobacco plants) in (A) pBI-BZ1; (B) pBI-BZ2; (C) pBI-BZ3; (D) pBI-BZ1 (T1 generation); (E) pBI-BZ2 (T1 generation); Data were expressed as the mean as the mean \pm SEM of three independent experiments; Analyses were performed using Student's t-tests. ${ }^{*} \mathrm{p}<0.05,{ }^{* *} \mathrm{p}<0.01,{ }^{* * *} \mathrm{p}<0.001$.

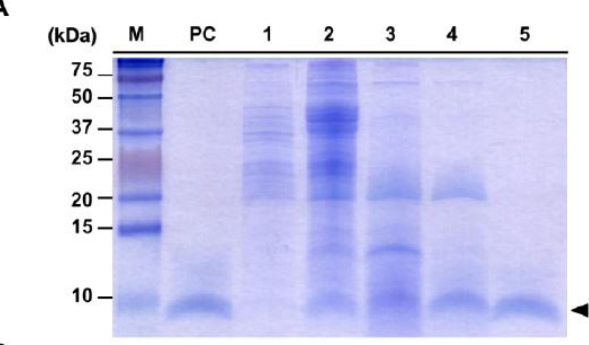

C

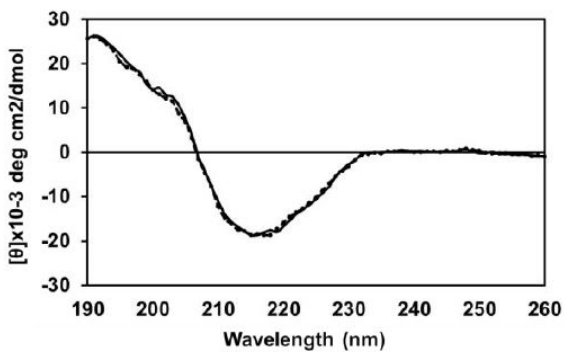

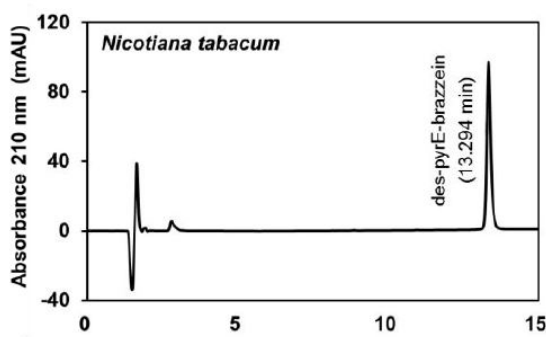

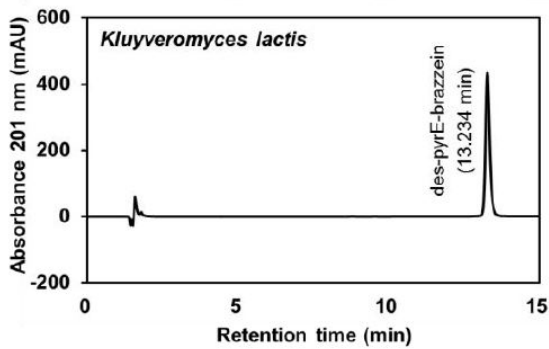

Figure 4. Confirmation of the purified brazzein in pBI-BZ2 transgenic tobacco plants. (A) SDS-PAGE analysis of the purified brazzein expressed in transgenic tobacco plants; lane $\mathrm{M}=$ molecular weight standard marker; $\mathrm{PC}$ = positive control (the brazzein minor form expressed in K. lactis); lane 1 = crude extracts; lane 2 = ammonium sulfate precipitation; lane 3 = heat treatment; lane 4 = DEAE-sepharose chromatography; lane 5 = CM-sepharose chromatography; (B) Reversed-phase HPLC patterns of the purified brazzein expressed in transgenic tobacco (N. tabacum) (upper panel) and K. lactis (lower panel); (C) Circular dichroism spectra of the purified brazzein expressed in transgenic tobacco (N. tabacum) (solid line) and K. lactis (dotted line).

purification, although this method did not completely eliminate proteins larger than $10 \mathrm{kDa}$.

Anion exchange chromatography improved the brazzein purification yield, which has a $\mathrm{pI}$ of 5.4 (Assadi-Porter et al., 2000). Under these conditions, most of the brazzein did not bind to the DEAE-sepharose resin and passed through the column (Supplementary Figure S2C). These results indicate that
DEAE-sepharose anion exchange chromatography can be used to remove contaminating proteins of $12 \mathrm{kDa}$ and larger than $30 \mathrm{kDa}$, although the brazzein cannot completely be purified by this method.

Brazzein purified by CM-sepharose cation exchange chromatography was confirmed by SDS-PAGE and appeared as a single band, with an apparent $\mathrm{M}_{\mathrm{r}}$ of $6.5 \mathrm{kDa}$ (Figure $4 \mathrm{~A}$ ). 
Table 2. Confirmation of the purified brazzein in pBI-BZ2 transgenic tobacco plants by N-terminal amino acid sequence and ESI-MS/MS analysis.

\begin{tabular}{cc}
\hline \multicolumn{2}{c}{ N-terminal amino acid sequence analysis } \\
\hline Sequence origin & First 5 amino acids of N-terminal \\
Brazzein minor form & DKCKK \\
Brazzein expressed from pBI-BZ2 & DKXKK \\
$\mathrm{X}$ indicates a cycle in which an amino acid assignment could not be made.
\end{tabular}

$\mathrm{X}$ indicates a cycle in which an amino acid assignment could not be made. ESI-MS/MS analysis

\begin{tabular}{ccc}
\hline & Amino acid sequences of brazzein minor form & CNYDCKLDKH \\
DKCKKVYENY & PVSKCQLANQ & ARSGECFYDE \\
KRNLQCICDY & CEY & \\
Bold text indicates brazzein amino acid sequences confirmed by ESI-MS/MS analysis. & \\
\hline
\end{tabular}

\subsection{The conformational state and identity of brazzein}

The purity and conformational state of the brazzein expressed in transgenic tobacco leaves was evaluated by HPLC and circular dichroism. The elution time for the expressed brazzein was almost the same as that of the expressed brazzein from K. lactis, $13.3 \pm 0.4$ min by reversed-phase HPLC, indicating only folded recombinant brazzein (Figure $4 \mathrm{~B}$ ). The $\mathrm{CD}$ spectrum of the brazzein expressed in transgenic tobacco leaves revealed a secondary structure composed of $9.9 \%$ a-helices and $19.7 \%$ $\beta$-strands (Figure $4 \mathrm{C}$ ), which is in similar to that of the expressed brazzein from $K$. lactis.

To confirm the successive secretory production of the designed recombinant brazzein in transgenic tobacco leaves, the $N$-terminal amino acids of the purified brazzein were determined by automated Edman degradation. The N-terminal amino acid sequence of the brazzein expressed in transgenic tobacco leaves was $\mathrm{D}-\mathrm{K}-\mathrm{X}-\mathrm{K}-\mathrm{K}$, corresponding to that deduced from the minor form of the brazzein gene (Table 2). The unassigned third amino acid " $\mathrm{X}$ " might correspond to a cysteine residue, which is not easily identified during automated $\mathrm{N}$-terminal amino acid sequencing analysis (Kruft et al., 1991). To identity the brazzein expressed in transgenic tobacco leaves, the internal amino acid sequences of the brazzein were confirmed by LC-ESI-MS/MS. The amino acid sequence of the internal peptide, SGECFYDEKR, corresponded to that deduced from the minor form of the brazzein gene (Table 2 ). Taken together, the identity of the brazzein expressed in transgenic tobacco leaves was confirmed by N-terminal amino acid analysis and ESI-MS/MS.

\subsection{Sweetness analysis of recombinant brazzein}

The sweetness of the purified brazzein expressed in transgenic tobacco leaves was evaluated by a human taste panel using a double-blind test. The estimated threshold value of the brazzein expressed in transgenic tobacco leaves was approximately $2.39 \times 10^{-3} \mathrm{mg} \mathrm{ml}^{-1}$; the protein was approximately 1330 times sweeter than sucrose on a weight basis. This result indicates that the purified brazzein in transgenic tobacco leaves has the sweetness of native brazzein.

\section{Discussion}

Recently, the use of plants as bioreactors for the commercial production of a number of valuable proteins has increased, with advantages including simple medium and culture condition requirements (Pham et al., 2012). Transgenic plants carrying the sweet tasting thaumatin II have been developed to improve and modify the taste of various plants including potato (Witty, 1990), cucumber (Szwacka et al., 2002), tomato (Bartoszewski et al., 2003), pear (Lebedev et al., 2000), and strawberry (Schestibratov \& Dolgov, 2005). However, the expression levels of thaumatin in these transgenic plants are low, although the CaMV 35S promoter that is active in various plant organs is used in these expression systems (Masuda \& Kitabatake, 2006). Monellin has also been produced with a $23.9 \mu \mathrm{g} \mathrm{g}^{-1}$ fresh weight yield in transgenic tomato and lettuce plants using a fruit-specific E8 promoter and CaMV 35S promoter, respectively (Peñarrubia et al., 1992). Miraculin was also successfully produced with a yield ranging from 33.7 to $43.5 \mu^{-1} g^{-1}$ fresh weight in transgenic lettuce plants using pBI121 or pBE2113-GUS that contained the CaMV $35 \mathrm{~S}$ promoter and the nopaline synthase gene promoter and terminator (Sun et al., 2006).

Transgenic tobacco plants are appealing for recombinant protein expression for a number of reasons. Tobacco can accumulate relatively large amounts of recombinant protein, as tobacco is a large crop of $2-3 \mathrm{~m}$. Additionally, there is no cross-contamination when using this crop. Therefore, we generated a transgenic tobacco plant (Nicotiana tabacum) that expressed the sweet-tasting protein, brazzein. We designed and constructed three types of expression vectors, $\mathrm{pBI}-\mathrm{BZ1}$, $\mathrm{pBI}-\mathrm{BZ2}$, and $\mathrm{pBI}-\mathrm{BZ} 3$, to improve brazzein production level and purification yield (Figure 2A, B). The expression levels of brazzein in transgenic plants containing $\mathrm{pBI}-\mathrm{BZ} 1$ and pBI-BZ2 were higher than those containing pBI-BZ3, in which the recombinant brazzein was expressed in the cell cytosol. A similar result was observed in a study examining brazzein expression in transgenic maize (Lamphear et al., 2005). This result demonstrates that the brazzein was efficiently expressed in pBI-BZ2 transgenic tobacco plants, and its expressed amount was significantly higher than those of miraculin in transgenic strawberry ( 0.5 to $\left.2.0 \mathrm{mg} \mathrm{kg}^{-1}\right)$ (Sugaya et al., 2008) and monellin in transgenic tomato and lettuce $\left(23.9 \mathrm{mg} \mathrm{kg}^{-1}\right)$ (Peñarrubia et al., 1992). These low brazzein expression levels in transgenic plants containing $\mathrm{pBI}-\mathrm{BZ} 3$ are believed to be due to the structural stability of the expressed protein. When the protein has multiple intramolecular disulfide bonds, it is difficult to achieve proper folding in the cytosol as it is a highly reducing environment. The $\mathrm{pBI}-\mathrm{BZ} 3$ expression vector did not have the SP sequence that plays a key role in targeting expression 
to the endoplasmic reticulum. Therefore, the recombinant brazzein containing four disulfide bridges was expressed in cytosol as an inclusion body (result not shown). Previous studies examining brazzein expression in E. coli reported that the recombinant brazzein expressed in the cytoplasm of E. coli exists in an insoluble form (Assadi-Porter et al., 2000, 2008). A similar result has been reported in soybean, in which the SP sequence enhanced HBsAg protein accumulation in the NT-1 plant cell line (Sojikul et al., 2003). Based on these results, brazzein expression in transgenic tobacco containing $\mathrm{pBI}-\mathrm{BZ} 1$ and $\mathrm{pBI}-\mathrm{BZ} 2$ should prove useful for the production of large amounts of active and soluble brazzein.

In this study, we successfully expressed and purified the recombinant brazzein in first-generation transgenic plants (T1) using ammonium sulfate precipitation, heat treatment, DEAE-sepharose anion chromatography, and CM-sepharose cation chromatography (Figure 4A). The results of our ammonium sulfate precipitation experiment were similar to the 30 and $85 \%$ ammonium sulfate saturation successfully used in a previous study (Ming \& Hellekant, 1994). The low yield was due to the isolation method and four purification steps, especially CM-sepharose cation chromatography. Therefore, the brazzein purification yield from transgenic tobacco leaves can be increased by optimizing the isolation and purification methods. We suggest a brazzein purification method from transgenic tobacco leaves using four steps: $30-80 \%$ ammonium sulfate precipitation, heat treatment at $80{ }^{\circ} \mathrm{C}$ for $2 \mathrm{~h}$, DEAE-sepharose anion chromatography, and $\mathrm{CM}$-sepharose cation chromatography, despite the fact that the yield was greatly reduced by CM-sepharose cation chromatography (Supplementary Figure S2C). To maximize the brazzein purification yield from transgenic tobacco leaves, the conditions of cation exchange chromatography, including the capacity of the $\mathrm{CM}$-sepharose cation exchange resin, $\mathrm{NaCl}$ concentration in the wash buffer, and $\mathrm{pH}$ of the elution buffer, should be optimized.

The conformational state and identity of the expressed recombinant brazzein were confirmed by HPLC, $\mathrm{CD}, \mathrm{N}$-terminal amino acid sequencing analysis, LC-ESI-MS/MS, and sweetness analysis. The elution time by reversed-phase HPLC (Figure 4B) and $\mathrm{CD}$ spectrum (Figure $4 \mathrm{C}$ ) for the brazzein expressed in transgenic tobacco leaves was almost the same as that of the expressed brazzein from $\mathrm{K}$. lactis, demonstrating the correct conformational state of the recombinant brazzein expressed in our T1 generation transgenic tobacco plants. The identity of the brazzein expressed in the $\mathrm{T} 1$ generation transgenic tobacco plants was confirmed by $\mathrm{N}$-terminal amino acid analysis and ESI-MS/MS (Table 2). The identity of the brazzein was also confirmed by sweetness analysis, although a small difference was seen between the sweetness intensity of the brazzein expressed in transgenic tobacco leaves and that in K. lactis. Compared to different concentrations of sucrose solutions, the sweetness intensity of the purified brazzein was as potent as the natural one. The brazzein expressed in transgenic tobacco leaves was approximately 1330 times sweeter than sucrose on a weight basis, and approximately 25200 times sweeter on a molar basis. In a previous study, the recombinant brazzeins of the minor form expressed in E. coli and K. lactis were approximately 1840 (using a double blind taste test) and 720 times (using the refined SIAM yes-no task) sweeter than sucrose on a weight basis (Lee et al., 2019, 2010). These differences in sweetness intensity may be due to different taste methods, protein purity, and other posttranslational modification. Small structural differences were also seen in the CD spectra of the brazzeins expressed in transgenic tobacco leaves and $K$. lactis (Figure 4C). Although no gross change in the secondary structure was suggested in the $\mathrm{CD}$ spectra comparison of the brazzein expressed in transgenic tobacco leaves and that in K. lactis, the contribution of a minor conformational change to the increase in sweetness could not be ruled out. These results suggest that the brazzein expressed in transgenic tobacco leaves has the correct brazzein folding pattern according to HPLC, CD, and sweetness analyses.

\section{Conclusions}

In conclusion, the brazzein content of the generated transgenic tobacco plants was confirmed, purified, and identified by various methods and analyses. Our results provide an economic mass-production system for this sweet-tasting protein, brazzein, with potential use as an alternative sweetener in the food industry.

\section{Conflict of interest}

The authors declare no competing financial interest.

\section{Funding}

This work was supported by a National Research Foundation of Korea Grant funded by the Korean Government (no. 2018R1D1A1B07043467 and NRF-2021R1F1A1062534) and Chung-Ang University Research Grants in 2020.

\section{Author Contributions}

Kwang-Hoon Kong and Sungguan Hong established the comprehensive research project for the brazzein plant expression system and led the study. Hyo-Eun Choi and Kwang-Hoon Kong conceived and designed the experiments with the help of Sungguan Hong, Kisung Ko, and Jeong-Hwan Lee. Hyo-Eun Choi and Yun-Cheol Chae generated the transgenic tobacco plants, and performed the qRT-PCR, and ELISA analyses. Hyo-Eun Choi purified the anti-brazzein antibody with the help of Hyeon-Jin Sun. Hyo-Eun Choi, Ji-In Lee, and Seon-Yeong JO performed the brazzein purification and SDS-PAGE experiments. Ji-In Lee conducted reverse-phase HPLC, CD, N-terminal amino acid analysis, ESI-MS/MS, and sweetness test. Hyo-Eun Choi wrote the draft, and Kwang-Hoon Kong and Sungguan Hong revised the manuscript.

\section{References}

Assadi-Porter, F. M., Aceti, D. J., Cheng, H., \& Markley, J. L. (2000). Efficient production of recombinant brazzein, a small, heat-stable, sweet-tasting protein of plant origin. Archives of Biochemistry and Biophysics, 376(2), 252-258. http://dx.doi.org/10.1006/abbi.2000.1725. PMid:10775410.

Assadi-Porter, F. M., Patry, S., \& Markley, J. L. (2008). Efficient and rapid protein expression and purification of small high disulfide containing sweet protein brazzein in E. coli. Protein Expression 
and Purification, 58(2), 263-268. http://dx.doi.org/10.1016/j. pep.2007.11.009. PMid:18221889.

Bartoszewski, G., Niedziela, A., Szwacka, M., \& Niemirowicz-Szczytt, K. (2003). Modification of tomato taste in transgenic plants carrying a thaumatin gene from Thaumatococcus daniellii Benth. Plant Breeding, 122(4), 347-351. http://dx.doi.org/10.1046/j.1439-0523.2003.00864.x.

Berlec, A., Jevnikar, Z., Majhenic, A. C., Rogelj, I., \& Strukelj, B. (2006). Expression of the sweet-tasting plant protein brazzein in Escherichia coli and Lactococcus lactis: a path toward sweet lactic acid bacteria. Applied Microbiology and Biotechnology, 73(1), 158-165. http:// dx.doi.org/10.1007/s00253-006-0438-y. PMid:16703320.

Chung, J. H., Kong, J. N., Choi, H. E., \& Kong, K. H. (2018). Antioxidant, anti-inflammatory, and anti-allergic activities of the sweet-tasting protein brazzein. Food Chemistry, 267, 163-169. http://dx.doi. org/10.1016/j.foodchem.2017.06.084. PMid:29934152.

Datla, R. S., Bekkaoui, F., Hammerlindl, J. K., Pilate, G., Dunstan, D. I., \& Crosby, W. L. (1993). Improved high-level constitutive foreign gene expression in plants using an AMV RNA4 untranslated leader sequence. Plant Science, 94(1-2), 139-149. http://dx.doi. org/10.1016/0168-9452(93)90015-R.

Jo, H. J., Noh, J. S., \& Kong, K. H. (2013). Efficient secretory expression of the sweet-tasting protein brazzein in the yeast Kluyveromyces lactis. Protein Expression and Purification, 90(2), 84-89. http://dx.doi. org/10.1016/j.pep.2013.05.001. PMid:23684772.

Kang, Y.J., Kim, D.S., Myung, S.C., \& Ko, K. (2017). Expression of a Human Prostatic Acid Phosphatase (PAP)-IgM Fc Fusion Protein in Plants Using In vitro Tissue Subculture. Front Plant Sci, 8, 274. https://doi.org/10.3389/fpls.2017.00274.

Kant, R. (2005). Sweet proteins--potential replacement for artificial low calorie sweeteners. Nutrition Journal, 4(1), 5. http://dx.doi. org/10.1186/1475-2891-4-5. PMid:15703077.

Kruft, V., Kapp, U., \& Wittmann-Liebold, B. (1991). On-sequencer pyridylethylation of cysteine residues after protection of amino groups by reaction with phenylisothiocyanate. Analytical Biochemistry, 193(2), 306-309. http://dx.doi.org/10.1016/0003-2697(91)90026-P. PMid:1872475.

Lamphear, B. J., Barker, D. K., Brooks, C. A., Delaney, D. E., Lane, J. R., Beifuss, K., Love, R., Thompson, K., Mayor, J., Clough, R., Harkey, R., Poage, M., Drees, C., Horn, M. E., Streatfield, S. J., Nikolov, Z., Woodard, S. L., Hood, E. E., Jilka, J. M., \& Howard, J. A. (2005). Expression of the sweet protein brazzein in maize for production of a new commercial sweetener. Plant Biotechnology Journal, 3(1), 103-114. http://dx.doi.org/10.1111/j.1467-7652.2004.00105.x. PMid:17168903.

Lebedev, V., Taran, S., Shmatchenko, V., \& Dolgov, S. (2000). Pear transformation with the gene for supersweet protein thaumatin II. In L. Corelli-Grappadelli, J. Janick, S. Sansavini, M. Tagliavini, D. Sugar, \& A.D. Webster (Eds.), VIII International Symposium on Pear 596 (pp. 199-202). Bologna, Italy: Acta Horticulturae.

Lee, H.-M., Park, S.-W., Lee, S.-J., \& Kong, K.-H. (2019). Optimized production and quantification of the tryptophan-deficient sweet-tasting protein brazzein in Kluyveromyces lactis. Preparative Biochemistry \& Biotechnology, 49(8), 790-799. http://dx.doi.org/10.1080/10826 068.2019.1621892. PMid:31140364.

Lee, J.-J., Kong, J.-N., Do, H.-D., Jo, D.-H., \& Kong, K.-H. (2010). Design and efficient soluble expression of a sweet protein, brazzein and minor-form mutant. Bulletin of the Korean Chemical Society, 31(12), 3830-3833. http://dx.doi.org/10.5012/bkcs.2010.31.12.3830.

Lee, Y. R., Akter, S., Lee, I. H., Jung, Y. J., Park, S. Y., Cho, Y.-G., Kang, K. K., \& Jung, Y. J. (2018). Stable expression of brazzein protein, a new type of alternative sweetener in transgenic rice. Journal of Plant Biotechnology, 45(1), 63-70. http://dx.doi.org/10.5010/ JPB.2018.45.1.063.

Masuda, T., \& Kitabatake, N. (2006). Developments in biotechnological production of sweet proteins. Journal of Bioscience and Bioengineering, 102(5), 375-389. http://dx.doi.org/10.1263/jbb.102.375. PMid:17189164.

Ming, D., \& Hellekant, G. (1994). Brazzein, a new high-potency thermostable sweet protein from Pentadiplandra brazzeana $B$. FEBS Letters, 355(1), 106-108. http://dx.doi.org/10.1016/00145793(94)01184-2. PMid:7957951.

Peñarrubia, L., Kim, R., Giovannoni, J., Kim, S.-H., \& Fischer, R. L. (1992). Production of the sweet protein monellin in transgetic plants. Bio/Technology, 10(5), 561-564.

Pham, N. B., Schafer, H., \& Wink, M. (2012). Production and secretion of recombinant thaumatin in tobacco hairy root cultures. Biotechnology Journal, 7(4), 537-545. http://dx.doi.org/10.1002/biot.201100430. PMid:22125283.

Poirier, N., Roudnitzky, N., Brockhoff, A., Belloir, C., Maison, M., Thomas-Danguin, T., Meyerhof, W., \& Briand, L. (2012). Efficient production and characterization of the sweet-tasting brazzein secreted by the yeast Pichia pastoris. Journal of Agricultural and Food Chemistry, 60(39), 9807-9814. http://dx.doi.org/10.1021/ jf301600m. PMid:22958103.

Schestibratov, K., \& Dolgov, S. (2005). Transgenic strawberry plants expressing a thaumatin II gene demonstrate enhanced resistance to Botrytis cinerea. Scientia Horticulturae, 106(2), 177-189. http:// dx.doi.org/10.1016/j.scienta.2005.03.016.

Shin, C., Kang, Y., Kim, H. S., Shin, Y. K., \& Ko, K. (2019). Immune response of heterologous recombinant antigenic protein of viral hemorrhagic septicemia virus (VHSV) in mice. Anim Cells Syst, 23(2), 97-105. http://dx.doi.org/10.1080/19768354.2019.1575904 . PMid:30949396.

Sojikul, P., Buehner, N., \& Mason, H. S. (2003). A plant signal peptidehepatitis B surface antigen fusion protein with enhanced stability and immunogenicity expressed in plant cells. Proceedings of the National Academy of Sciences of the United States of America, 100(5), 22092214. http://dx.doi.org/10.1073/pnas.0438037100. PMid:12601177.

Song, I., Kang, Y. J., Choi, S. L., Han, D., Kim, D. S., Lee, H. K., Lee, J. C., Park, J., Kim, D. S., \& Ko, K. (2019). Purification of plant-derived anti-virus $\mathrm{mAb}$ through optimized $\mathrm{pH}$ conditions for coupling between protein A and epoxy-activated beads. PeerJ, 7, e6828. http:// dx.doi.org/10.7717/peerj.6828. PMid:31149395.

Sugaya, T., Yano, M., Sun, H.-J., Hirai, T., \& Ezura, H. (2008). Transgenic strawberry expressing the taste-modifying protein miraculin. Plant Biotechnology, 25(4), 329-333. http://dx.doi.org/10.5511/ plantbiotechnology.25.329.

Sun, H.-J., Cui, M., Ma, B., \& Ezura, H. (2006). Functional expression of the taste-modifying protein, miraculin, in transgenic lettuce. FEBS Letters, 580(2), 620-626. http://dx.doi.org/10.1016/j.febslet.2005.12.080. PMid:16406368.

Szwacka, M., Krzymowska, M., Osuch, A., Kowalczyk, M. E., \& Malepszy, S. (2002). Variable properties of transgenic cucumber plants containing the thaumatin II gene from Thaumatococcus daniellii. Acta Physiologiae Plantarum, 24, 173-185. http://dx.doi. org/10.1007/s11738-002-0009-5.

Wintjens, R., Viet, T. M., Mbosso, E., \& Huet, J. (2011). Hypothesis/ review: the structural basis of sweetness perception of sweet-tasting plant proteins can be deduced from sequence analysis. Plant Science, 181(4), 347-354. http://dx.doi.org/10.1016/j.plantsci.2011.06.009. PMid:21889040. 
Witty, M. (1990). Preprothaumatin II is processed to biological activity inSolanum tuberosum. Biotechnology Letters, 12, 131-136. http:// dx.doi.org/10.1007/BF01022429.

Yan, S., Song, H., Pang, D., Zou, Q., Li, L., Yan, Q., Fan, N., Zhao, X., Yu, H., Li, Z., Wang, H., Gao, F., Ouyang, H., \& Lai, L. (2013). Expression of plant sweet protein brazzein in the milk of transgenic mice. PLoS One, 8(10), e76769. http://dx.doi.org/10.1371/journal. pone.0076769. PMid:24155905.

Yun, C. R., Kong, J. N., Chung, J. H., Kim, M. C., \& Kong, K. H. (2016), Improved secretory production of the sweet-tasting protein, brazzein, in Kluyveromyces lactis. Journal of Agricultural and Food Chemistry, 64(32), 6312-6316. http://dx.doi.org/10.1021/acs.jafc.6b02446. PMid:27465609. 


\section{Supplementary Material}

Supplementary material accompanies this paper.

Supplementary Figure S1. Confirmation of the mRNA expression level of brazzein in transgenic tobacco plants.

Supplementary Figure S2. SDS-PAGE analysis for expressed brazzein purification in transgenic tobacco plants.

This material is available as part of the online article from http://www.scielo.br/cta 